\title{
Synthesis of the studies about the transmission cycle of malaria in an area of very low incidence outside the Amazon Region in Brazil
}

\author{
Crispim Cerutti $\mathrm{Jr}^{1 *}$, Aloísio Falqueto ${ }^{1}$, Helder Ricas Rezende ${ }^{4}$, Renata Soares ${ }^{2}$, Isabel Alves ${ }^{2}$, Delsio Natal ${ }^{2}$, \\ Paulo Roberto Urbinatti ${ }^{2}$, Tasciane Yamasaki ${ }^{2}$, Ana Maria Ribeiro de Castro Duarte ${ }^{3}$, Rosely dos Santos Malafronte ${ }^{2}$ \\ From $16^{\text {th }}$ International Symposium on HIV and Emerging Infectious Diseases \\ Marseille, France. 24-26 March 2010
}

\section{Background}

To describe malaria transmission cycle in an area of residual occurence in Brazil.

\section{Methods}

Survey of cases reported from April 2001 to March 2004. Blood sampling of inhabitants (two kilometers around the cases). ELISA for antibodies against the Circunsporozoite protein (CSP) of Plasmodium vivax and its variants, and Plasmodium malariae. Blood smears. Indirect Fluorescent Antibody (IFA) test for crude blood stage antigens of $P$. vivax, $P$. malariae and Plasmodium falciparum. Protein chain reaction (PCR) for amplification of the DNA of P. vivax, P. malariae and P. falciparum (Rubio's protocol). Mosquitoes captures with $\mathrm{CDC}-\mathrm{CO} 2$ traps placed in the canopy and in the ground inside the forest and at its margin, as in the open field. Shannon light traps at the margin of the forest. PCR of the macerated mosquitoes for DNA of Plasmodium (Kimura's protocol) (thorax and abdomen tested separately).

\section{Results}

Sixty-five patients and 1,777 inhabitants evaluated. Patients were $35.11+/-16$ years old in average and most of them were males $(78.5 \%)$. There were no case clusters. P. vivax (morphology and PCR) in 47 of 48 patients, and P. malariae in the remainder. Anti-CSP antibodies for $P$. vivax, its variants and $P$. malariae in high frequency in the patients and in the inhabitants. IFA positive for IgM against $P$. malariae in 40 of
253 samples from the inhabitants (15.8\%) and in 113 of 253 for IgG antibodies (44.6\%). Figures for $P$. vivax were 105 of 1,701 (IgM ) (6.2\%) and 641 of 1,701 (37.7\%) (IgG). PCR from the inhabitants revealed $P$. vivax in 23 , $P$. malariae in 15, P. falciparum in 9 and P. falciparum plus P. malariae in one. Anopheles cruzii had an acrodendrophylic behavior (90\% of the specimens captured in the canopy). DNA of Plasmodium was amplified in several species of anopheline mosquitoes.

\section{Discussion}

Predominance of males and absence of vectors nearby the houses favor an extradomiciliary transmission. Absence of clusters and distance among the cases point out to the existence of a silent reservoir. Two possibilities: asymptomatic human reservoir (not important in our survey) and simian reservoir (close relation between cases and the forest; acrodendrophylic beahvior of the main vector).

\section{Author details}

'Universidade Federal do Espírito Santo, Vitória, Brazil. ${ }^{2}$ Universidade de São Paulo, São Paulo, Brazil. ${ }^{3}$ Superintendência de Controle de Endemias, São

Paulo, Brazil. ${ }^{4}$ SESA, Vitória, Brazil.

Published: 11 May 2010

doi:10.1186/1742-4690-7-S1-P183

Cite this article as: Cerutti et al: Synthesis of the studies about the transmission cycle of malaria in an area of very low incidence outside the Amazon Region in Brazil. Retrovirology 2010 7(Suppl 1):P183.

\footnotetext{
* Correspondence: fil.cris@terra.com.br

'Universidade Federal do Espírito Santo, Vitória, Brazil
} 